\title{
Buğday Ekili Parsellerde NDVI Değerlerinin Konumsal ve Zamana Bağlı Değişiminin
} Belirlenmesi

Kemal Sulhi GÜNDOĞDU1 in

${ }^{1}$ Uludağ Üniversitesi, Ziraat Fakültesi, Biyosistem Mühendisliği Bölümü, Bursa

$\bowtie$ : kemalg@uludag.edu.tr

\section{ÖZET}

Tarımsal üretimde, uzaktan algılama teknikleri kullanılarak bitki gelişimin takibi yaygın olarak kullanılmaya başlanılmıştır. Uydu ve hava görüntüleri ile insansız hava araçlarından alınan görüntüler, bitkinin arazide gelişiminin konumsal takibinde kolaylıklar sağlamaktadır. Bitki yeşil aksamının yoğunluğunun ve türünün belirlenmesinde bitkilerden yansıyan kırmızı ve yakın kızılötesi bant görüntüleri kullanılarak bitki örtüsü indeksi olarak NDVI değeri hesaplanmaktadır.

$\mathrm{Bu}$ çalışmada, Uludağ Üniversitesi Ziraat Fakültesi çiftlik arazisinde 2015-2016 üretim döneminde Pehlivan çeşidi buğday ekili alanlarda NDVI değerlerinin zamana ve konuma göre değişiminin belirlenmesi amaçlanmıştır. Çalışmada farklı tarihlerde çekilmiş Landsat 8 görüntüleri kullanılmıştır. Parsel bazında yapılan değerlendirme sonucunda parsel içerisinde bitki örtü indeksi değerlerinin homojen bir dağılım göstermediği görülmüştür.
DOI: 10.18016/ksudobil.364749

\author{
Makale Tarihçesi \\ Geliş : 11.12 .2017
}

Kabul : 05.02.2018

\author{
Anahtar Kelimeler \\ NDVI, \\ Buğday, \\ Pehlivan
}

Araştırma Makalesi

\section{Determination of Temporal and Spatial Changes of NDVI Values on Wheat Planted Plots}

\begin{abstract}
In agricultural production, generally the remote sensing techniques have begun to be used on follow-up of plant development in a widespread manner. Images taken from satellite, airplane and unmanned aerial vehicles provide facilities for the spatial follow-up of the plant's development in the field. For determination of the plant intensity and species, NDVI values is calculated as vegetation index by using images taken in the red and near infrared wavelength reflecting from the plants. In this study, it was aimed to determine the spatial and temporal change of NDVI values in Pehlivan wheat variety planted in farm of Agricultural Faculty, Uludağ University during $2015-2016$ production period. Landsat 8 images taken at different dates were used in the study. As a result of the plot-based evaluation, the vegetation index values in the parcel did not show a homogeneous distribution.
\end{abstract}

\section{Article History \\ Received: 11.12 .2017 \\ Accepted: 05.02.2018}

\section{Keywords \\ NDVI, \\ Wheat, \\ Pehlivan}

\section{Research Article}

To Cite : Gündoğdu KS 2018. Buğday Ekili Parsellerde NDVI Değerlerinin Konumsal ve Zamana Bağlı Değişiminin Belirlenmesi. KSÜ Tarım ve Doğa Derg 21(4):492-499, DOI: 10.18016/ksudobil.364749.

\section{GíRIŞ}

Bitkiler, yapraklarında bulunan klorofil maddesini ve gün ışığını inorganik maddeden organik madde üretmek için kullanırlar. Fotosentez diye anılan bu işlem esnasında Güneş'ten gelen elektromanyetik enerjinin $0,63 \mu \mathrm{m}-0,69 \mu \mathrm{m}$ dalga boyunda olan ve kırmızı ışığa karşılık gelen kısmı kullanılır. $\mathrm{Bu}$ yüzden, kırmızı ışığın yansımasını ölçen bir uydu görüntüsü, canlı bitki örtüsünün yoğun olduğu alanlarda düşük sayısal değerlere sahip olacaktır. Öte yandan bitkiler $0,7 \mu \mathrm{m}$ ve daha yüksek dalga boyuna sahip elektromanyetik enerjiyi bünyelerine almaz, geri yansitırlar. Dolayısıyla, canlı bitki örtüsünün yoğun olduğu alanlar, yakın kızılötesi elektromanyetik enerjinin yansımasını ölçen bir uydu görüntüsünde yüksek sayısal değerlere sahip olacaktır (Benek ve Şahap, 2017).

Normalize edilmiş fark bitki örtüsü indeksi (Normalized difference vegetation index, NDVI) kırmızı ve yakın kızılötesi bant görüntüleri kullanılarak üretilir. Her piksel için o piksele ait yakın kızılötesi bant yansıma değerinden aynı piksele ait kırmızı bant yansıma değeri çıkartılır. Bu fark, bitki örtüsü yoğun alanlar için bitki örtüsü seyrek alanlara göre daha fazla olacaktır. Farkları alınan bu iki değerin toplanması ve farkın toplama bölünmesi ile [- 
$1,+1]$ aralığında bir değer elde edilir. Yeni bir 8- bitlik görüntü oluşturmak için bu aralığın [0,255] aralığına genişletilmesi gerekir, bu işleme de normalize etme denir (Kandemir, 2010). NDVI değeri aşağıdaki formül ile hesaplanmaktadır.

NDVI $=(\mathrm{NIR}-\mathrm{RED}) /(\mathrm{NIR}+\mathrm{RED})$

Burada, NIR ışık spektrumun yakın kızılötesi dalga boyunu $(0.68-0.78 \mu \mathrm{m})$, RED ise kırmızı bölge dalga boyunu $(0.61-0.68 \mu \mathrm{m})$, NDVI (birimsiz) ise vejetasyon indeks değerini temsil etmektedir (Tucker, 1979).

NDVI değerleri teorik olarak (-1) ile $(+1)$ arasında değişmektedir. Yeşil bitki örtüsünün fazla olduğu alanlarda indeks değeri +1'e doğru yaklaşırken, bulutlar, su ve kar düşük (eksi) NDVI indeks değerlerine sahiptir. Çıplak toprak ve zayıf bitki örtüsü durumunda ise sıfıra yakın NDVI değeri gösterir (Hatfield ve Ark., 1985). Bir NDVI haritasında tarımın yoğun olduğu bölgeler gözlendiğinde, düşük NDVI değerlerine sahip alanlar kuraklık, aşırı rutubet, hastalık ve zararlılar gibi çeşitli nedenlerle zayıf bitki gelişiminin olduğu bölgeleri işaret etmektedir. Diğer taraftan yüksek NDVI değerleri ise bitki gelişiminin sağlıklı olduğu yerleri göstermektedir (Yıldız ve Ark., 2012).

NDVI verileri, özellikle geniş alanlardaki bitki örtüsünün incelenmesinde birçok bilim adamı tarafından dünyanın çeşitli bölgelerinde başarıyla kullanılmıştır. NDVI hesaplamalarında uydu görüntülerinin kullanılması, geniş alanların birlikte değerlendirilebilmesi nedeniyle, çalışma maliyetini düşürücü unsur olmaktadır (Marsh ve Ark., 1992). Böylece ülke bazında çalışmalar kolaylıkla yürütülebilmektedir. Karabulut (2006), NDVI verilerinden faydalanarak Türkiye'de belli başlı bitki örtüsü gruplarının yıl içerisinde değişimini araştırmıştır. Yüksek biomas karakterine sahip orman alanları yıl boyunca yüksek indeks değerine sahip olurken, tam tersi olarak daha düşük biomas özellikleri nedeniyle otsu bitkiler düşük indeks değerleri ile ifade edildiğini belirtmiş̧tir. Otsu bitkilerin İç Anadolu'da Mayıs-Haziran, Doğu Anadolu'da ise Haziran-Temmuz aylarında kısa süreli olarak yüksek indeks değerleri gösterdiğini bulmuştur.

Topraktan olan NIR dalga boyundaki yansıma değerleri düşük, kırmızı dalga boyundaki yansıma değerleri yüksek olduğundan, seyrek bitki örtüsü ile kaplı alanlarda düşük NDVI değerleri elde edilmektedir (Gandhi ve Ark., 2015).
$\mathrm{Bu}$ çalışmada, Uludağ Üniversitesi Ziraat Fakültesi çiftlik arazisinde 2015-2016 üretim döneminde yetiştiriciliği yapılan Pehlivan çeşidi buğday ekili alanlarda NDVI değerlerinin zamana ve konuma göre değişimi belirlenmiştir. Ziraat Fakültesi arazisinde belirtilen üretim döneminde, Pehlivan çeşidi Buğday, 9 ile 56 dekar arasında değişen alana sahip parsellerde ekilmiştir. Çalışmanın amacı, küçük alana sahip olan bu parsellerdeki NDVI değerleri üzerinde sınır etkisinin olup olmadığının ve parsellerdeki buğday verim değerleri ile NDVI değerleri arasında bir korelasyonun olup olmadığının belirlenmesidir. Başka araştırıcılar tarafından yapılan çalışmalar ele alındığında, küçük alana sahip parsellerde, her parselin ayrı ayrı değerlendirildiği çalışmalar oldukça azdır. Son yıllarda yaygınlaşmaya başlayan hassas tarım uygulamalarında parsel bazlı çalışmalar yapılmaya başlanmıştır. Bu çalışmada 30 metre çözünürlüğe sahip Landsat uydu görüntüleri kullanılmıştır. NDVI hesaplamalarında bir uzaktan algilama paket programı kullanılmayıp, amaca uygun bir yazılım, Python programlama dilinde hazırlanmıştır.

\section{MATERYAL}

Çalışmada, Uludağ Üniversitesi Ziraat Fakültesi Çiftliği arazilerini kapsayan Landsat uydu görüntüleri kullanılmıştır. Kullanılan görüntüler, 2015-2016 buğday üretim dönemini kapsayacak biçimde, 06/09/2015, 27/12/2015, 01/04/2016, 17/04/2016, 04/06/2016, 06/07/2016 ve 22/07/2016 tarihlerinde çekilmiş görüntülerdir. Bazı aylardaki görüntüler alınamamış, alınabilen yukarıda sayılan görüntüler üzerinde çalışılmıştır. Çiftlik arazisinde 2015-2016 üretim döneminde Pehlivan çeşidi Buğday ekimi gerçekleştirilen parseller, çalışmanın materyalini oluşturmuştur. Buğday ekim tarihi Ekim-2015, hasat tarihi ise Temmuz-2016 dır. Çalışma alanını oluşturan $10,11,15,17,20,21,22,23,26$ ve 27 nolu parseller sirasiyla $48,40,56,29,18,39,37,9,26$ ve 34 da alan kaplamaktadırlar (Şekil 1). Parsellerin kapladığ alanın sol alt köşe koordinatı $40^{\circ} 13^{\prime} 45^{\prime \prime}$ Kuzey$28^{\circ} 50^{\prime} 58^{\prime \prime}$ Doğu, sağ üst köşe koordinatı $40^{\circ} 15^{\prime} 06^{\prime \prime}$ Kuzey-28 $51^{\prime} 32^{\prime \prime}$ Doğu enlem ve boylamları arasındadır (Şekil 1). Görüntülerin görselleştirilmesi ve bazı analizlerin yapılabilmesi için ArcGIS ver 10.2 coğrafi bilgi sistemi programı kullanılmıştır. NDVI değerlerinin hesaplanması için Python ver 2.7 programlama dili ile hazırlanan yazılım kullanılmıştır. Parsellerin bulunduğu alanda ölçülen yağış değerleri Çizelge 1'de verilmiştir. 

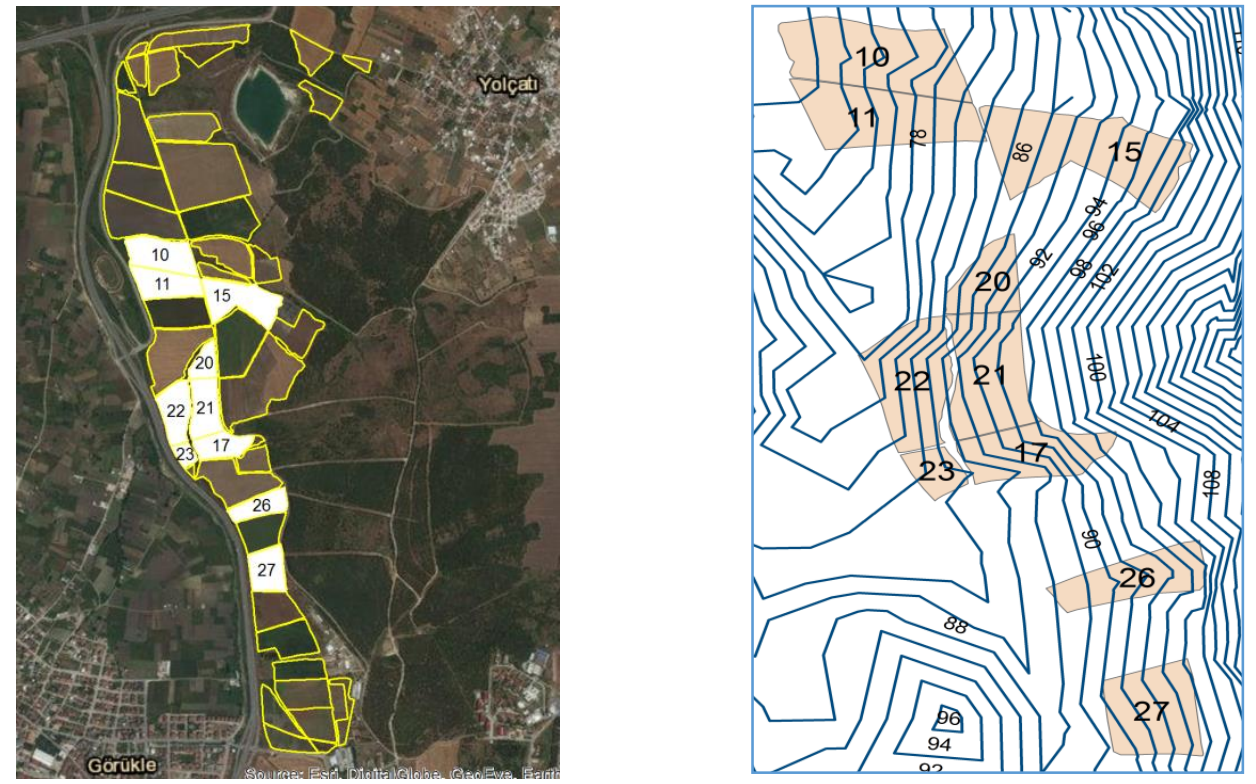

Şekil 1. Çalışma alanını oluşturan 10, 11, 15, 17, 20, 21, 22, 23, 26 ve 27 nolu parsellerin konumu ve eş yükseklik eğrileri

Çizelge 1. Görükle Tarbil İstasyonunda ölçülen 2015 ve 2016 yılları aylık yağış değerleri

\begin{tabular}{|r|r|r|}
\hline Yıl & Ay & Yağış, $\mathbf{~ m m}$ \\
\hline 2015 & 7 & 0.0 \\
\hline 2015 & 8 & 1.0 \\
\hline 2015 & 9 & 56.0 \\
\hline 2015 & 10 & 95.6 \\
\hline 2015 & 11 & 25.2 \\
\hline 2015 & 12 & 4.6 \\
\hline 2016 & 1 & 37.2 \\
\hline 2016 & 2 & 61.0 \\
\hline 2016 & 3 & 58.8 \\
\hline 2016 & 4 & 3.4 \\
\hline 2016 & 5 & 63.8 \\
\hline 2016 & 6 & 18.8 \\
\hline 2016 & 7 & 0.2 \\
\hline
\end{tabular}

\section{YÖNTEM}

Uludağ Üniversitesi Ziraat Fakültesi çiftlik arazisinde, 2015-2016 üretim döneminde Pehlivan çeşidi buğday yetiştiriciliği yapılan parsellerde farklı tarihlerde alınan uydu görüntülerinden NDVI bitki indeksi hesaplanmış, konumsal ve zamana göre değişimi incelenmiştir. Uzaktan algılama görüntülerinde, görüntünün kullanımı üzerinde etkili faktörlerden birisi görüntünün çekildiği tarihteki bulutluluk düzeyidir. Çalışılacak alan üzerinde bulutların bulunduğu görüntüler, sadece bulut yansıması vereceğinden bitkisel ürünler için bir değerlendirme yapılamamaktadır. Bu kısıt nedeniyle, bulutluluk düzeyleri düşük ve bulutların çalışma bölgesini kaplamadığı uydu görüntüleri kullanılmıştır. Uludağ Üniversitesi Ziraat Fakültesi çiftçiliğindeki parseller WGS_1984_UTM_Zone_35N projeksiyon sistemine göre ArcGIS ortamında sayısallaştırılmıştır. Sayısallaştırılmış parseller için öznitelik tablosu oluşturularak, parsel bilgileri öz nitelik tablosuna girilmiştir.

Landsat 8 uydu görüntülerinin 4. bandı kırmızı(RED), 5 . bandı yakın kızıl ötesi(NIR) yansımaları içermektedir. Çalışmada kullanılan 7 uydu görüntüsü için, NDVI hesabı Python programlama dilinde hazırlanan program ile gerçekleştirilmiş, her uydu görüntüsü için bir tane olmak üzere NDVI değerlerini içeren haritalar elde edilmiştir. Landsat görüntüleri $30 * 30 \mathrm{~m}$ çözünürlükte veriler içerdiğinden, oluşan NDVI dosyası da aynı çözünürlüğe sahiptir.

Çalışma materyalini oluşturan Pehlivan çeşidi buğday ekimi gerçekleştirilen parseller, poligon özelliklidir. Her parselin içerisindeki farklı konumlardaki NDVI değerini alabilmek için, poligon özellikli parsel dosyası, NDVI dosyasinin koordinat sistemi kullanılarak $30 * 30 \mathrm{~m}$ çözünürlükte raster formatına dönüştürülmüştür. Uydu görüntüleri path ve row ifadeleri ile tanımlanmaktadır. Çalışma da, Path = 180 , Row $=32$ olan uydu görüntüleri kullanılmıştır. Farklı tarihlerde alınan uydu görüntüleri, aynı path ve row değerine sahip olmalarına karşın farklı minimum ve maksimum koordinat (mapextent) değerine sahip olabilmektedirler. $\mathrm{Bu}$ durum oluşacak raster hücrelerinin koordinatını değiştirebilmektedir. Bu sebeple, her uydu görüntüsünün koordinat sistemi ve mapextent değerleri kullanılarak parseller raster formatına çevrilmiştir. Diğer uydu görüntüleri ile çalışırken işlemler tekrar edilmiştir. Raster formatına dönüştürülmüş parsel dosyası ile NDVI dosyası ilişkilendirilmiş ve parsellerin farklı konumlarından pikseller için NDVI değerleri okunarak, piksel koordinatları ve NDVI değerleri bir dosyaya aktarılmıştır.

Elde edilen dosya, ArcMAP yazılımına aktarılarak, 30 metre aralıklarla noktalardan oluşan bir harita elde 
edilmiştir. NDVI değerlerinden, yüzey haritası elde etmek için düzensiz üçgenler ağı (TIN) oluşturulmuştur. Düzensiz üçgenler ağı dosyası, $1 \mathrm{~m}$ çözünürlükte olacak biçimde ArcMAP ortamında raster dosyası haline dönüştürülmüştür. Raster dosyasından, parsel sınırları dışındaki olan değerlerin çıkarılması için, poligon özellikli parsel dosyası (shape dosya türü formatında) kullanılmıştır. NDVI değerlerinin konumsal dağglımının daha iyi görülebilmesi için ayrıca eş NDVI değeri haritaları üretilmiştir.

\section{ARAŞTIRMA SONUÇLARI ve TARTIŞMA}

Uydu görüntülerinden $30 * 30$ metre aralıklarla hesaplanan NDVI değerlerinin konumları Şekil 2'de verilmiştir. Şekilde, uydu görüntülerini oluşturan piksellerin merkez noktası verilmiştir. Her noktanın konumuna ait NDVI değeri ArcMAP ortaminda öznitelik tablosuna eklenmiştir (Şekil 3). Şekil 3'de NDVI değerlerini içeren nokta özellikli ArcMAP shape dosyasının öznitelik tablosu verilmiştir. Bu dosyadaki her kayıt, parselin numarasını, piksel koordinatını ve tüm uydu görüntüleri için NDVI değerlerini içermektedir.

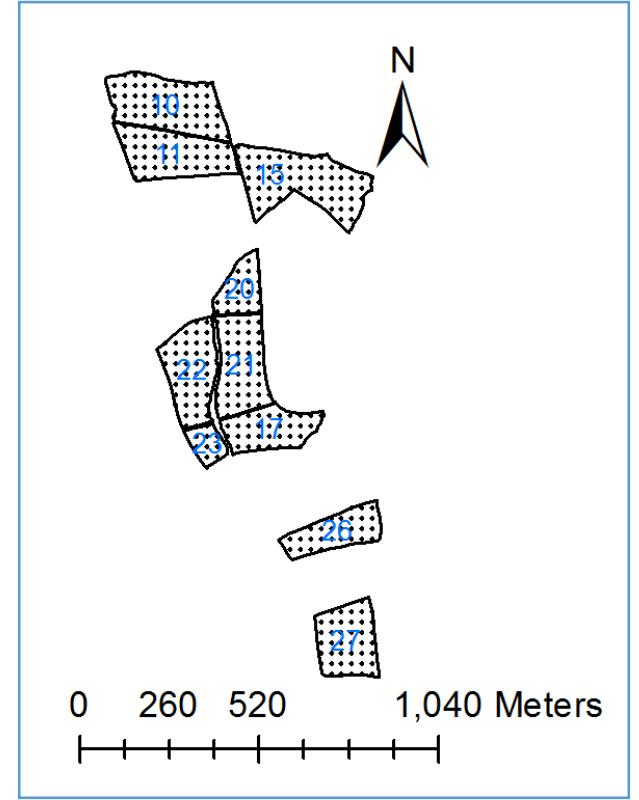

Şekil 2. 30*30 metre aralıklarla hesaplanan NDVI değerlerinin konumları

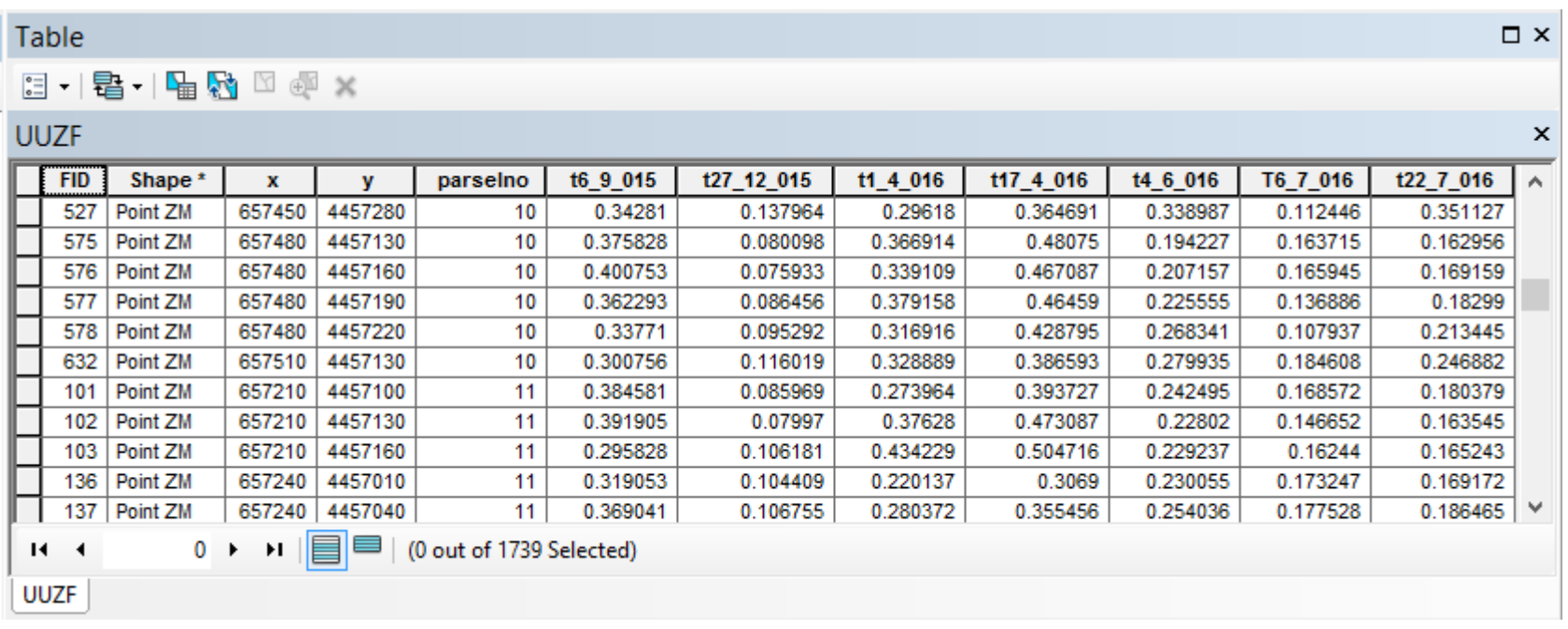

Şekil 3. NDVI değerlerini içeren nokta (Point) özellikli ArcMAP dosyasının öznitelik tablosu

Bu dosyadaki NDVI değerleri kullanılarak, Sekil 4'de verilen konumsal dağılım haritaları elde edilmiştir. Tüm haritalara ayrı ayrı bakıldığında, parsel sınırları ile parsel içerisindeki NDVI değerlerini ifade eden renklerin farklı olduğu görülmektedir. Pehlivan çeşidi buğday yetiştirilen parsellerde homojen bir NDVI değeri dağılımı görülmemektedir. Parsel sınırları sanki bir çizgi ile belirgin hale getirilmiş gibi görünmektedir. Bunun yanında, parsel sınırlarından parsel merkezine doğru gidildiğinde, NDVI değerini ifade eden rengin kademeli olarak değiştiği gözlenmektedir. $\mathrm{Bu}$ durum, parsellerdeki NDVI değerlerinin sınır etkisi nedeniyle değiştiğini göstermektedir. Parsel sinırlarına yakın konumlardaki NDVI değerleri ile parsel merkezindeki NDVI değerlerinin birbirinden farklı olduğu gözlenmektedir. 


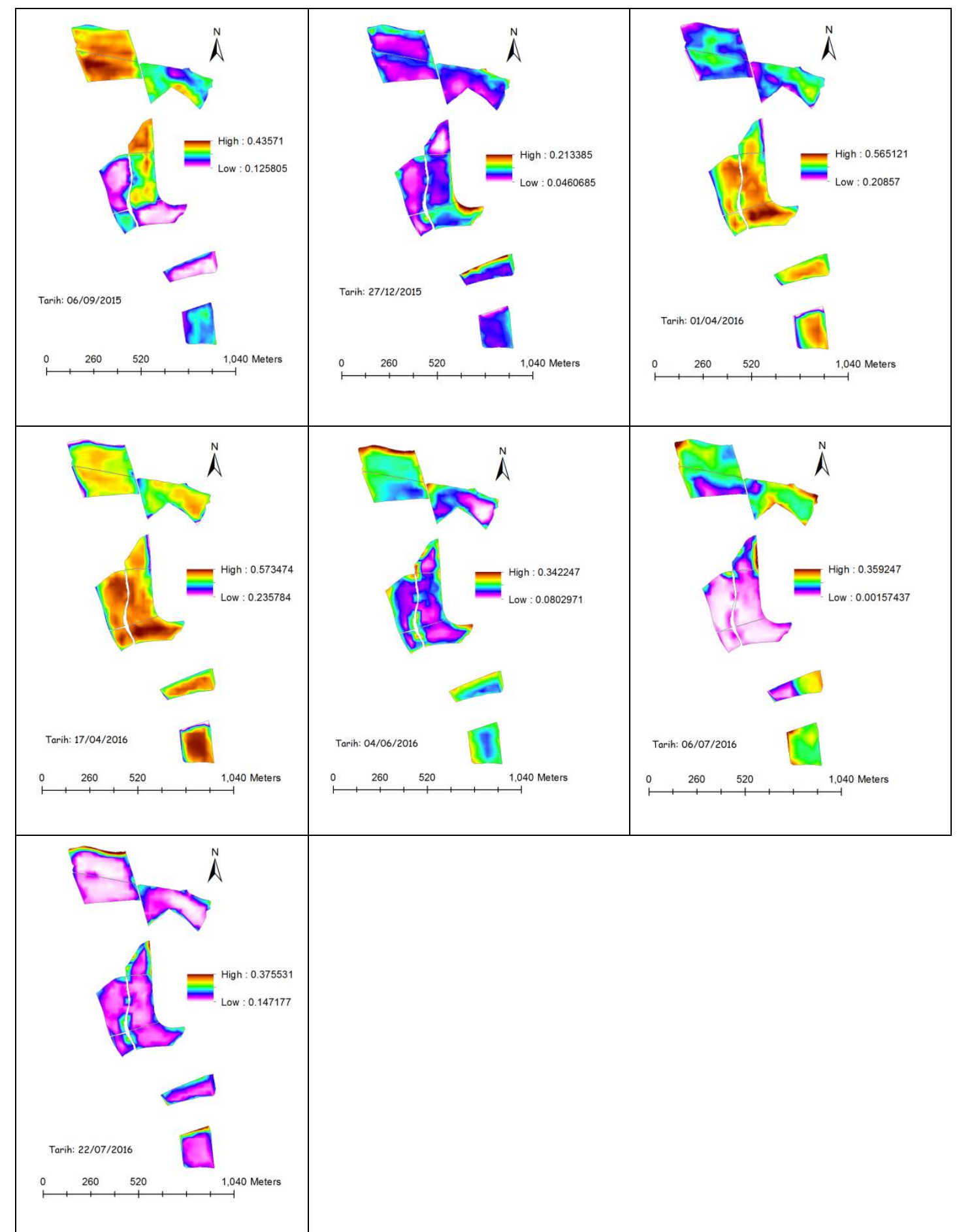

Şekil 4. Farklı tarihlerdeki uydu görüntülerinden hesaplanan NDVI değerleri dağılımı

Şekil 4'de görüldüğü gibi 17/04/2016 tarihinde parsellerin hepsinde NDVI değerleri, diğer görüntülere göre daha yüksek elde edilmiştir. $\mathrm{Bu}$ durum bu tarihte daha fazla yeşil aksamın olduğunu göstermektedir. 06/09/2015 tarihinde henüz buğday ekimi yapılmamıştır. Bu tarihte 10,11, 20, 21 ve 15 nolu parsellerde yeşil aksaml bitkilerin olduğu görülmektedir. Bu bitkinin yonca olduğu, buğday ekiminin Ekim ayında yonca parselleri bozularak gerçekleştirildiği, çiftlik yetkililerince ifade edilmiştir. 27/12/2015 tarihli uydu görüntüsünde görüleceği gibi arazide bazı parsel sınırları hariç yeşil aksamlı bitkilerin olmadığı görülmektedir. Yeşil aksamlı bitkilerde, NDVI değerleri 0.2 ve daha fazla olmaktadır. Bu değer ile 0.05 arasında kalan değere sahip alanlar çiplak toprak olarak siniflandirılabilmektedir. Bulutluluk ise 0.02-0.05 aralığında NDVI değeri vermektedir (Maxwell ve Sylvester, 2012).

Parsel bazında her uydu görüntüsünden elde edilen NDVI değerlerinin maksimum, minimum ve ortalama değerleri Çizelge 2'de verilmiştir. Gerek parseller ayrı 
ayrı gerekse tüm parseller dikkate alındığında maksimum ve minimum değerler arasında önemli farklılıkların olduğu görülmüştür. İlk uydu görüntüsünde NDVI değerleri 0.1257 ile 0.4362 arasında değişmektedir. En fazla yeşil aksamın bulunduğu zaman olan Nisan ayının başında NDVI değerleri 0.2201 ile 0.5656 arasında, Nisan ayının ikinci yarısında ise NDVI değerleri 0.2809 ile 0.5737 arasında değişmiştir. Parsel içerisinde NDVI değerlerinin geniş bir aralıkta değişmesi, parsellerin küçük olması ve parsel sınır etkisinin fazla olmasindan kaynaklanabilecektir. Sinırdan uzaklaştıkça görülen farklılık ise, toprak bitki besin elementlerinin konumsal farklılığının sonucu olabilecektir. Arazi gübreleme işlemleri gübreleme makinesi ile gerçekleştirilmektedir. $\mathrm{Bu}$ makinenin parsellerin sınırlarına arazinin diğer bölümleri ile homojen bir gübre dağıtımı yapması zordur. $\mathrm{Bu}$ nedenle parsel sınırlarındaki bitki gelişimi ile arazinin diğer bölümlerindeki bitki gelişimi farklı olabilmektedir. Parsel çevre uzunluğunun olabildiğince az olması için, parsellerin birleştirilerek parsel alanının arttırılması, uygun olmayan parsel şeklinin makineli tarım tekniğine uygun bir şekilde düzenlenmesi, hem işletme masraflarını azaltacak hem de homogen bir ürün elde edilmesini sağlayacaktır. Hassas tarım uygulamalarının etkin bir şekilde yapılabilmesi için parsel büyüklüklerinin arttırılması ve şekillerinin dikdörtgen olarak oluşturulması gerekmektedir. Gübreleme işlemi ise konuma bağlı olarak planlanmalıdır.

Çizelge 2. Parsellerde farklı tarihli uydu görüntülerinden hesaplanan NDVI değerlerinin maksimum, minimum ve ortalama değerleri

\begin{tabular}{|c|c|c|c|c|c|c|c|c|}
\hline \multirow[b]{2}{*}{ Parsel No } & \multirow[b]{2}{*}{ NDVI } & \multicolumn{7}{|c|}{ Uydu Görüntüleri } \\
\hline & & 6.9.2015 & 27.12.2015 & 1.4.2016 & 17.4.2016 & 4.6.2016 & 6.7.2016 & 22.7.2016 \\
\hline \multirow{3}{*}{10} & Maksimum & 0.40451 & 0.13796 & 0.44238 & 0.51041 & 0.34193 & 0.26561 & 0.36272 \\
\hline & Minimum & 0.23407 & 0.0589 & 0.29618 & 0.28094 & 0.19314 & 0.1005 & 0.14867 \\
\hline & Ortalama & 0.36058 & 0.08446 & 0.36432 & 0.46667 & 0.2358 & 0.1596 & 0.18873 \\
\hline \multirow{3}{*}{11} & Maksimum & 0.43628 & 0.1119 & 0.44096 & 0.5179 & 0.25404 & 0.17753 & 0.20679 \\
\hline & Minimum & 0.26922 & 0.06221 & 0.22014 & 0.30696 & 0.15779 & 0.03309 & 0.15049 \\
\hline & Ortalama & 0.38175 & 0.07992 & 0.3727 & 0.48024 & 0.19979 & 0.10926 & 0.16137 \\
\hline \multirow{3}{*}{15} & Maksimum & 0.37866 & 0.13339 & 0.47309 & 0.52606 & 0.31586 & 0.31777 & 0.26449 \\
\hline & Minimum & 0.16693 & 0.05934 & 0.30162 & 0.38396 & 0.0807 & 0.0417 & 0.14714 \\
\hline & Ortalama & 0.27532 & 0.08209 & 0.38769 & 0.47815 & 0.16154 & 0.16051 & 0.1762 \\
\hline \multirow{3}{*}{17} & Maksimum & 0.25337 & 0.18837 & 0.56565 & 0.57373 & 0.30911 & 0.06823 & 0.24438 \\
\hline & Minimum & 0.12578 & 0.07947 & 0.38596 & 0.42366 & 0.11564 & 0.06676 & 0.16509 \\
\hline & Ortalama & 0.16112 & 0.11078 & 0.50029 & 0.52982 & 0.1667 & 0.0208 & 0.18672 \\
\hline \multirow{3}{*}{20} & Maksimum & 0.40712 & 0.11316 & 0.49766 & 0.52805 & 0.31708 & 0.28205 & 0.30264 \\
\hline & Minimum & 0.30024 & 0.04676 & 0.29531 & 0.3211 & 0.11055 & 0.01972 & 0.15984 \\
\hline & Ortalama & 0.36767 & 0.07133 & 0.42405 & 0.47819 & 0.18938 & 0.11803 & 0.21098 \\
\hline \multirow{3}{*}{21} & Maksimum & 0.40998 & 0.14378 & 0.53011 & 0.54932 & 0.28484 & 0.16361 & 0.25506 \\
\hline & Minimum & 0.21985 & 0.0696 & 0.37684 & 0.4059 & 0.12033 & 0.06625 & 0.15605 \\
\hline & Ortalama & 0.31828 & 0.08489 & 0.4857 & 0.51168 & 0.16315 & 0.03185 & 0.17673 \\
\hline \multirow{3}{*}{22} & Maksimum & 0.27554 & 0.1195 & 0.5304 & 0.5519 & 0.2875 & 0.21618 & 0.2615 \\
\hline & Minimum & 0.13702 & 0.0596 & 0.32395 & 0.38652 & 0.10979 & 0.00146 & 0.16215 \\
\hline & Ortalama & 0.18073 & 0.0763 & 0.46488 & 0.51242 & 0.17533 & 0.03055 & 0.18413 \\
\hline \multirow{3}{*}{23} & Maksimum & 0.2892 & 0.14005 & 0.53058 & 0.55708 & 0.29445 & 0.05936 & 0.27161 \\
\hline & Minimum & 0.2074 & 0.05356 & 0.37619 & 0.42837 & 0.11092 & 0.00566 & 0.16215 \\
\hline & Ortalama & 0.2601 & 0.0796 & 0.46896 & 0.51817 & 0.1824 & 0.02033 & 0.1941 \\
\hline \multirow{3}{*}{26} & Maksimum & 0.2809 & 0.17166 & 0.52064 & 0.54367 & 0.27979 & 0.22567 & 0.26359 \\
\hline & Minimum & 0.12934 & 0.07434 & 0.42333 & 0.39953 & 0.15559 & 0.0149 & 0.16363 \\
\hline & Ortalama & 0.16443 & 0.09817 & 0.47674 & 0.50757 & 0.21181 & 0.12932 & 0.18761 \\
\hline \multirow{3}{*}{27} & Maksimum & 0.29652 & 0.11263 & 0.52672 & 0.55994 & 0.27556 & 0.23383 & 0.32009 \\
\hline & Minimum & 0.19129 & 0.05729 & 0.25402 & 0.28101 & 0.16587 & 0.13064 & 0.16077 \\
\hline & Ortalama & 0.24135 & 0.08478 & 0.44781 & 0.50695 & 0.21075 & 0.17141 & 0.18668 \\
\hline \multirow{3}{*}{$\begin{array}{c}\text { Tüm } \\
\text { Parseller }\end{array}$} & Maksimum & 0.4362 & 0.1883 & 0.5656 & 0.5737 & 0.3419 & 0.3177 & 0.3627 \\
\hline & Minimum & 0.1257 & 0.0467 & 0.2201 & 0.2809 & 0.08 & 0.0014 & 0.1471 \\
\hline & Ortalama & 0.27109 & 0.08518 & 0.43925 & 0.49893 & 0.18963 & 0.09514 & 0.18529 \\
\hline
\end{tabular}

Şekil 4'de verilen gösterimin yanında, NDVI değerlerinin konumsal değişimi, eş NDVI değerleri şeklinde de gösterilebilmektedir (Şekil 5). Burada, aynı NDVI değerlerine sahip konumlar birleştirilerek, eş NDVI haritaları elde edilebilmektir. Şekil 5'de, 01/04/2016 tarihli uydu görüntüsü kullanılarak 17, 20, 21, 22, ve 23 nolu parseller için elde edilen eş NDVI eğrileri haritası örnek olarak verilmiştir. 


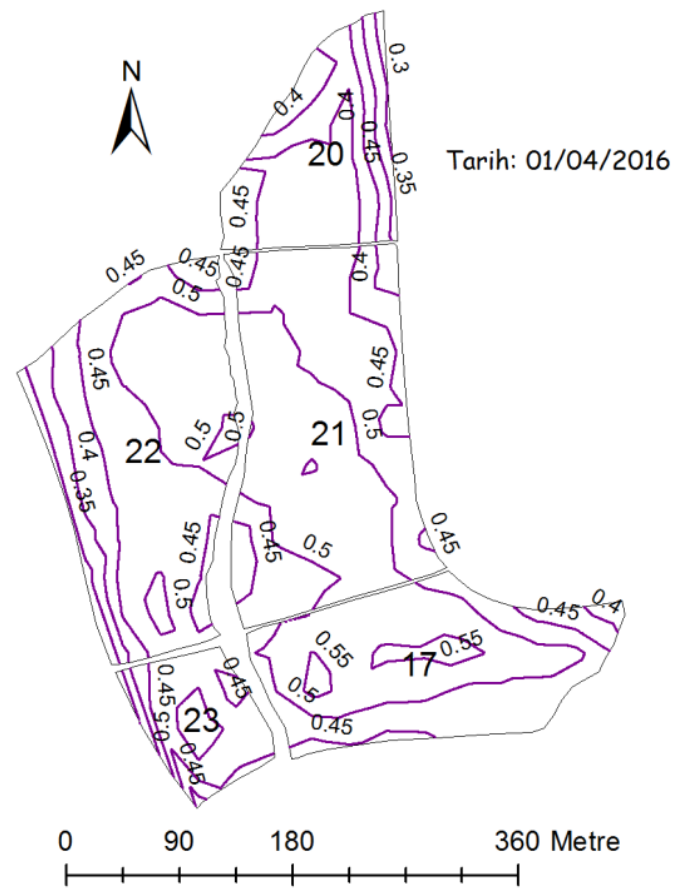

Şekil 5. NDVI değerlerinin eş NDVI eğrileri ile gösterimi

Parsellerde, ortalama NDVI değerine yaklaşan değerleri bulmak için, her parsel için NDVI değerleri küçükten büyüğe sıralanmıştır. Her parseldeki toplam veri sayısının ilk \%10'luk kısmı ile son \% 10'luk kısmı dışarıda bırakılarak, kalan değerlerin değişim aralığı ve bu parsellerden elde edilen verimler Çizelge 3 'de verilmiştir. Böylece parsellerde elde edilen ekstrem NDVI değerlerinden arındırılmış değerler ile çalışmanın daha doğru olacağı düşünülmüştür.

Verimler ile \%80'lik ortanca NDVI değerlerinin ortalaması arasında istatistiksel bir ilişkinin olup olmadiğı araştırılmıştır. Bu amaçla, tüm uydu görüntüleri için elde edilen ortalama değerler ile verim değerleri karşlıklı grafik kağıdına işlenmiş, uygun bir eğilim çizgisi oluşturmaya çalışlmıştır. Bunların arasında en yüksek $r^{2}$ değeri 0.059 olarak, 04/06/2016 tarihli görüntünün verilerinden elde edilmiştir. $\mathrm{R}^{2}$ değeri oldukça düşük elde edildiğinden eğilim çizgisinin denklemi burada verilmemiştir. Şimşek ve Ark. (2007) yürüttükleri çalışmada, AgroMetShell modelini kullanarak, Buğday'da veri tahmini yapmışlardır. $\mathrm{Bu}$ amaçla, meteorolojik veriler, bitki katsayıları, fenolojik gözlemler, toprak özellikleri ve NDVI görüntülerini kullanmışlardır. Tahmin edilen verim değerleri ile gerçekleşen değerler arasında $\mathrm{r}^{2}=$ 0.9067 düzeyinde bir ilişki tespit etmişlerdir. NDVI değerleri ile verim arasındaki ilişkinin araştırılacağı çalışmaların, büyük parsellerde ve geniş alanlarda gerçekleştirilmesi ile daha uygun sonuçlar elde edilebilecektir. Böylece parsel sınır etkisi azaltılmış olacaktır.

Çizelge 3. \%80 lik ortanca değerlerinin değişim aralıkları

\begin{tabular}{cccccccccc}
\hline \multicolumn{10}{c}{ Uydu Tarihi } \\
\hline Parsel No & \multicolumn{1}{c}{6.9 .2015} & 27.12 .2015 & 1.4 .2016 & 17.4 .2016 & 4.6 .2016 & 6.7 .2016 & 22.7 .2016 & verim kg/da \\
\hline 10 & $0.326-0.393$ & $0.066-0.112$ & $0.35-0.405$ & $0.377-0.504$ & $0.197-0.321$ & $0.112-0.192$ & $0.15-0.301$ & 413 \\
\hline 11 & $0.319-0.41$ & $0.066-0.093$ & $0.314-0.43$ & $0.417-0.508$ & $0.167-0.229$ & $0.052-0.16$ & $0.153-0.169$ & 413 \\
\hline 15 & $0.212-0.337$ & $0.065-0.096$ & $0.322-0.433$ & $0.431-0.506$ & $0.1-0.22$ & $0.108-0.211$ & $0.151-0.212$ & 369 \\
\hline 17 & $0.132-0.198$ & $0.085-0.14$ & $0.436-0.552$ & $0.475-0.562$ & $0.12-0.257$ & $0.008-0.046$ & $0.166-0.224$ & 427 \\
\hline 20 & $0.306-0.402$ & $0.047-0.091$ & $0.301-0.484$ & $0.369-0.519$ & $0.112-0.27$ & $0.021-0.265$ & $0.163-0.263$ & 427 \\
\hline 21 & $0.258-0.358$ & $0.074-0.096$ & $0.425-0.519$ & $0.478-0.537$ & $0.122-0.198$ & $0.008-0.044$ & $0.16-0.194$ & 427 \\
\hline 22 & $0.139-0.249$ & $0.061-0.097$ & $0.386-0.519$ & $0.448-0.548$ & $0.136-0.234$ & $0.007-0.047$ & $0.163-0.222$ & 400 \\
\hline 23 & $0.207-0.284$ & $0.054-0.101$ & $0.376-0.503$ & $0.428-0.54$ & $0.111-0.266$ & $0.006-0.026$ & $0.162-0.206$ & 400 \\
\hline 26 & $0.13-0.22$ & $0.075-0.144$ & $0.427-0.509$ & $0.433-0.54$ & $0.168-0.264$ & $0.02-0.204$ & $0.165-0.219$ & 400 \\
\hline 27 & $0.198-0.267$ & $0.074-0.092$ & $0.338-0.51$ & $0.422-0.555$ & $0.17-0.242$ & $0.145-0.206$ & $0.166-0.203$ & 480 \\
\hline
\end{tabular}

Çizelge 3'de görüleceği gibi, buğday ekiminin henüz yapılmadığı Eylül ayındaki görüntüde, NDVI değerleri 0.13 ile 0.41 arasında değişmektedir. Bu değerler arazide bitkilerin olduğunu göstermektedir. Aralık ayında alınan görüntüde ise NDVI değerleri 0.047 ile 0.144 arasında değişmektedir. Bu değerler arazide bitkisel yeşil aksamın olmadığını göstermektedir. Nisan başındaki görüntüde ise, 0.301 ile 0.552 arasındaki NDVI değeri arazide bitkisel aksamın yoğun bir şekilde olduğunu göstermektedir. Nisan ayının ikinci yarısında alınan görüntüde ise, NDVI değerleri 0.377 ile 0.562 arasında hesaplanmış, arazide yoğun bir bitki yeşil aksamının olduğunu göstermektedir. Mayıs ayında görüntü alınamamıştır. Haziran ayında ise, 0.1 ile 0.321 arasındaki NDVI değeri arazide bitkilerde azalma olduğunu göstermektedir. Temmuz ayının ilk yarısında 17, 20, 21, 22 ve 23 nolu parsellerde düşük NDVI değeri elde edilmiştir. Bu durum yeşil bitkilerin bu parsellerde olmadığını göstermektedir. Diğer parsellerde NDVI değerlerine göre, kısmi olarak yeşil bitki bulunduğu saptanmıştır. Temmuz ayının ikinci yarısındaki görüntüdeki NDVI değerleri tüm parseller için düşük olarak elde edilmiştir. Bu görüntüde NDVI değerleri 0.15 ile 0.263 arasindadır. Maxwell ve Sylvester (2012)'de belirtildiği gibi, NDVI değeri 0.2'den fazla 
olan alanlarda yeşil aksamlı bitkiler bulunmaktadır. Parsel sınırlarında kısmi olarak NDVI değeri yüksek alanlar bulunmaktadır (Şekil 4). Bu durum bazı parsellerin sınır bölgelerinde yeşil aksama sahip bitkilerin olduğunu göstermektedir. Parsellerin bulunduğu bölgede yapılan bir çalışmada, Değirmenci ve Korukçu (1992), arazinin düşük kotlu bölgelerinde taban suyu sorunu bulunabileceğini ve bazı gözlem kuyularında ortalama taban suyu derinliğinin $15.2 \mathrm{~cm}$ olduğunu belirtmişlerdir. Şekil 1'de verilen eş yükselti haritasında görüleceği gibi, bu alanlarda arazi kotu daha düşüktür. Haziran-2016 ve Temmuz-2016 aylarındaki yağış miktarına bakıldığında sırasıyla $18.8 \mathrm{~mm}$ ve $0.2 \mathrm{~mm}$ yağ 1 ş ölçülmüştür (Çizelge 1). Yağış miktarının oldukça düşük olması nedeniyle, sinırlardaki yeşil aksamın bu yağışlardan oluşmadığ düşünülmektedir. Çaldağ (2009) Trakya bölgesinde yürüttükleri çalışmada, buğday bitkisinde en yüksek ortalama NDVI değerinin 0.45 olarak bulmuştur. Çalışmamızda, bu değer 0.53 olarak elde edilmiştir. Teke ve Yardımcı (2016) yürüttükleri çalışmada, Harran Ovası'nda yetişen buğday, mısır ve pamuk ürünlerinin Göktürk-2 uydusundan alınan görüntülerden tespiti üzerinde çalışmışlardır. Buğday bitkisi için yılın 100, 120, 160, 170 ve 185 . günleri sirasiyla $0.7,0.62,0.45,0.25$ ve 0.18 NDVI değerlerini elde etmişlerdir.

Landsat 8 uydusu 16 günde bir aynı koordinatta çekim yapmaktadır. Uydu görüntülerinde bulutsuzluk oranının fazla olması istenmektedir. Ancak uygulamada, uydu görüntüsünün alındığ 1 zaman diliminde bazı aylar için bulutlu olma ihtimali vardır. $\mathrm{Bu}$ nedenle istenilen zaman diliminde düşük bulutluluk oranında görüntü almak zorlaşmaktadır. Son yıllarda, dron olarak adlandırılan insansız hava araçlarının uzaktan algılama amaçlı kullanımı yaygınlaşmaktadır. Dron üzerine takılan kırmızı, yakın kızıl ötesi kamera ile istenilen alanın görüntüleri çekilebilmektedir. Bulutlu havada bile bulutların altında çekim yapılabildiğinden, bulutluluk sorun olmaktan çıkmaktadır. Araziye daha yakın çekim gerçekleştirildiği için çözünürlük artmaktadır. Elde edilen görüntüler hassas tarım uygulamalarında kullanılabilmektedir. Çekilen fotoğraflar Pix4D gibi yazılımlarla birleştirilerek üzerinde çalışılması kolaylaştırılabilmektedir.

\section{TEŞEKKÜR}

$\mathrm{Bu}$ çalışma, Uludağ Üniversitesi Bilimsel Araştırma Projeleri Komisyonu tarafindan desteklenen KUAP(Z)2016/13 projesi kapsamında hazırlanmıştır.

\section{KAYNAKLAR}

Benek S, Şahap A 2017. Şanlıurfa Şehrinde Coğrafi Bilgi Sistemleri (Cbs) ve Uzaktan Algılama (Ua) Kullanılarak Yeşil Alanların Yeterliliğinin
Belirlenmesi. Marmara Coğrafya Dergisi, 36: 304314.

Çaldağ B 2009. Trakya Bölgesi'nin Tarımsal Meteorolojik Özelliklerinin Belirlenmesi. İstanbul Teknik Üniversitesi Fen Bilimleri Enstitüsü, Meteoroloji Mühendisliği Ana Bilim Dalı, Doktora Tezi, $257 \mathrm{~s}$.

Değirmenci H, Korukçu A 1992. Uludağ Üniversitesi Tarımsal Araştırma ve Uygulama Merkezi Arazisinin Drenaj Sorunları ve Çözüm Yolları Üzerinde Bir İnceleme. U.Ü. Zir. Fak. Dergisi， 9: 151-161.

Gandhi MG, Parthiban S, Thummalu N, Christy A 2015. Ndvi: Vegetation Change Detection Using Remote Sensing and GIS - A Case Study of Vellore District. Procedia Computer Science, 57: 1199 1210.

Hatfield JL, Kanemasu ET, Asrar G, Jackson RD, Pinter PJJ, Reginato RJ, Idso SB 1985. Leaf Area Estimates From Spectral Measurements Over Various Planting Dates of Wheat. Int. J. Remote Sens, 6: 167-175.

Kandemir E 2010. Uzaktan Algılama Tekniğinde NDVI Değerleri İle Doğal Bitki Örtüsü Tür Dağılımı Arasındaki İlişkilerin Belirlenmesi Üzerine Araştırmalar. Ege Üniversitesi, Fen Bilimleri Enstitüsü, Çevre Bilimleri Ana Bilim Dall, Yüksek Lisans Tezi, $60 \mathrm{~s}$.

Karabulut M 2006. NOAA AVHRR Verilerini Kullanarak Türkiye'de Bitki Örtüsünün İzlenmesi ve İncelenmesi. Coğrafi Bilimler Dergisi, 4(1): 2942.

Maxwell SK, Sylvester KM 2012. Identification of "Ever-Cropped" Land (1984-2010) Using Landsat Annual Maximum NDVI Image Composites: Southwestern Kansas Case Study. Remote Sensing of Environment, 121: 186-195.

Marsh SE, Walsh JL, Lee CT, Beck LR, Hutchinson CF 1992. Comparison of Multi-temporal NOAA AVHRR and SPOT-XS Satellite Data For Mapping Land Cover Dynamics in The West African Sahel. International Journal of Remote Sensing, 13(16): 2997-3016.

Şimşek O, Mermer A, Yıldız H, Özaydın KA, Çakmak B 2007. AgroMetShell Modeli Kullanılarak Türkiye'de Buğdayın Verim Tahmini. Tarım Bilimleri Dergisi, 13(3): 299-307.

Teke M, Yardımcı Y 2016. Göktürk-2 Zaman Serisi Görüntüleri ile Ürün Sinıflandırma. 24th Signal Processing and Communication Application Conference, 16-19 Mayıs, Zonguldak.

Tucker C 1979. Red and Photographic Infrared Linear Combination for Monitoring Vegetation. Remote Sensing of Environment, 8: 127-150.

Yıldız H, Mermer A, Ünal E, Akbaş F 2012. Türkiye Bitki Örtüsünün NDVI Verileri ile Zamansal ve Mekansal Analizi. Tarla Bitkileri Merkez Araştırma Enstitüsü Dergisi, 21(2): 50-56 